\title{
Impact of body mass index on critically ill COVID-19 patients admitted in a tertiary care hospital: A retrospective observational study
}

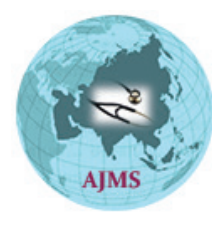

\author{
Savita Gupta ${ }^{1}$, Varun Goel ${ }^{2}$, Nazia Nazir ${ }^{3}$, Saurabh Srivastava ${ }^{4}$, Anurag Srivastava ${ }^{5}$ \\ ${ }^{1}$ Assistant Professor, ${ }^{3}$ Associate Professor, Department of Anaesthesia, ${ }^{2}$ Assistant Professor, Department of \\ Microbiology, ${ }^{4}$ Professor and Head, Department of Medicine, ${ }^{5}$ Associate Professor, Department of Community \\ Medicine, Government Institute of Medical Sciences, Greater Noida, Uttar Pradesh, India
}

Background: Increased body mass index (BMI) is a known risk factor for respiratory infection and is being recognized as a predisposing factor in the COVID-19 pandemic caused by the severe acute respiratory syndrome coronavirus-2. Aims and Objectives: This study aimed to assess the impact of BMI on critically ill COVID-19 patients. Secondary outcomes include development of respiratory failure, shock, acute cardiac injury, acute kidney injury, acute liver injury, secondary infection and sepsis. Materials and Methods: This retrospective study of 6 months included the laboratory-confirmed COVID-19 patients admitted to an ICU of a tertiary care academic health-care organization. The medical records were reviewed at least 14 days after admission. Results: A total of 484 patients were included, and BMI data were available for 306 patients. About $40.19 \%$ had a normal weight, $26.79 \%$ were overweight, $17.97 \%$ had BMI $30-34.9 \mathrm{Kg} / \mathrm{m}^{2}$, and $15.03 \%$ had $\mathrm{BMI} \geq 35 \mathrm{Kg} / \mathrm{m}^{2}$. Overall, 58 patients (18.95\%) died within 14 days of ICU admission, $50.98 \%$ were discharged alive or referred from the hospital within 14 days, and $30.06 \%$ remained hospitalized at 14 days. After controlling for all covariates, there was a significantly increased risk of mortality in the patients with obesity Class I (RR 2.03, 95\% Cl 1.07-3.85, P=0.030) and patients with obesity Classes II and III (RR 2.83, 95\% Cl 1.54-5.22, P<0.001) compared with those with normal BMI. Conclusion: Obesity was associated with an unfavorable outcome among patients with COVID-19. Patients with obesity should be more closely monitored when hospitalized for COVID-19 as there is increasing evidence of relation of severity of COVID-19 and obesity which appears to be a factor in the health risks.

Key words: Body mass index; COVID-19; Hospitalization; Obesity; Mortality; Pandemic

\section{Access this article online}

Website:

http://nepjol.info/index.php/AJMS DOI: 10.3126/ajms.v13i1.41396

E-ISSN: 2091-0576

P-ISSN: 2467-9100

Copyright (c) 2022 Asian Journal of Medical Sciences

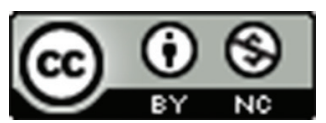

This work is licensed under a Creative Commons Attribution-NonCommercial 4.0 International License.

\section{INTRODUCTION}

COVID-19 clinical profile ranges from asymptomatic infection to severe acute respiratory infection requiring intensive care unit (ICU) facility and oxygen support..$^{1-3}$ Increased body mass index (BMI), already a known risk factor for respiratory infection, is increasingly being recognized in many studies as a predisposing factor in the COVID-19. ${ }^{4}$ This is an important consideration since excess weight, usually represented by a raised BMI, affects vast numbers of people around the world. As per the WHO estimates, $13 \%$ of adults have clinical obesity (BMI $\geq 30.0 \mathrm{~kg} / \mathrm{m}^{2}$ ) and $39 \%$ are overweight (BMI $\geq 25.0-29.9 \mathrm{~kg} / \mathrm{m}^{2}$ ) worldwide. ${ }^{5}$ In India, the prevalence rate of obesity varies from $11.8 \%$ to $31.3 \%$ as per one study. ${ }^{6}$

An increase in BMI is associated with severe forms of COVID-19 and may be a potential risk factor of ICU admission. In patients with ARDS as per some studies, an obesity survival paradox has been observed. This raises the question of whether the obesity paradox has been broken by COVID-19. ${ }^{7-9}$ It is, therefore, necessary to know if there is any relationship between obesity and COVID-19. 


\section{Aims and objectives}

As there is a paucity of original research data in Asian context, in the present study, we tried to know the association between BMI categories and severe COVID-19 requiring ICU or leading to death. Secondary outcomes include development of respiratory failure, shock, acute cardiac injury, acute kidney injury, acute liver injury, secondary infection and sepsis.

\section{MATERIALS AND METHODS}

The permission to conduct this study was taken from the Institutional Ethics Committee and the study was also registered with the Clinical Trial Registry-India (CTRI/2021/03/032226). In the present study, data were extracted retrospectively on consecutive adult patients admitted in ICU from June to November 2020 hospitalized with laboratory-confirmed COVID-19 at a tertiary care academic health-care organization. All COVID-19 patients were identified by real time reverse transcriptase-polymerase chain reaction (RT-PCR) in-house testing for SARS-CoV-2 on admission. The inclusion criteria were those who were 18 years or older with a confirmed diagnosis of COVID-19 by RT-PCR assay and inpatient admission. Exclusion criteria included pregnancy and no weight or height measurement available in the medical files. The data extracted from medical files included demographics, baseline comorbidity of diabetes, hypertension, main clinical data, and outcomes. Covariates were age, sex, diabetes mellitus, and hypertension measured on patient admission. All patients were assigned a unique identification code to maintain their confidentiality. Four BMI groups were classified:

Group 1 Normal

Group 2 Overweight

Group 3 Obese Class I

Group 4 Obese Classes II and III

BMI 18.5-24.9 kg/m² BMI 25-29.9 kg/m² BMI 30-34.9 kg/m²

The main outcome was death within 14 days of ICU admission. Any patient who was discharged alive from the hospital before 14 days was considered to be alive at 14 days. Other outcomes noted included the development of respiratory failure, acute kidney injury, and secondary bacterial infections.

\section{Statistical analysis}

Baseline demographics were expressed as the median (interquartile range) for numerical variables and the frequency (percentage) for categorical variables. Oneway analysis of variance was conducted to compare the mean difference among groups. Qualitative variables were described by percentages. Characteristics statistically significant at the 0.10 alpha level in bivariate analyses were included into the multivariable regression model. ${ }^{10}$ Data thus collected were entered into a computer-based spreadsheet for analysis using SPSS statistical software (version 21) (IBM Corp., NY, USA). P<0.05 was considered as statistically significant.

\section{RESULTS}

A total of 484 COVID-19-positive patients were admitted to ICU from which data on BMI were available for 306 patients. The rest of the patients were either $<18$ years of age or their BMI or case files were unavailable. The patients' baseline characteristics are shown as per the BMI category in Table 1.

There were 123 patients $(40.19 \%)$ with normal weight, $82(26.79 \%)$ with overweight BMI $25-29.9 \mathrm{Kg} / \mathrm{m}^{2}$, $55(17.97 \%)$ in obesity Class 1, and $46(15.03 \%)$ in obesity Classes II and III. Among 46 obesity Class II and III patients, 15 (4.90\%) belonged to Class III obesity (BMI $\geq 40.0 \mathrm{~kg} / \mathrm{m}^{2}$ ). The majority of patients were between 45 and 65 years of age with male predominance. The median age was significantly different between groups 58, 61, 59, and 54 years for normal weight, overweight, obesity Class I, and obesity Classes II and III, respectively; $\mathrm{P}<0.001$.

Diabetes was found to be highest in the BMI group $\geq 35 \mathrm{~kg} / \mathrm{m}^{2}$ and the lowest in the BMI with $18.5-24.9 \mathrm{~kg} / \mathrm{m}^{2}$. Hypertension was highest in the group with BMI 25-29.9 kg/m²; however, none of these was statistically significant.

\section{Table 1: Characteristics of the study population by BMI category ${ }^{a}$}

\begin{tabular}{|c|c|c|c|c|c|}
\hline Characteristic & $\begin{array}{c}\text { Group } 1 \\
\text { normal weight } \\
\text { BMI 18.5-24.9 kg/m²} \\
(\mathrm{N}=123)\end{array}$ & $\begin{array}{c}\text { Group } 2 \\
\text { overweight } \\
\text { BMI } 25-29.9 \mathrm{~kg} / \mathrm{m}^{2} \\
(\mathrm{~N}=82)\end{array}$ & $\begin{array}{c}\text { Group } 3 \\
\text { obese Class I } \\
\text { BMI } 30-34.9 \mathrm{~kg} / \mathrm{m}^{2}(\mathrm{~N}=55)\end{array}$ & $\begin{array}{c}\text { Group } 4 \\
\text { obese Classes II and III } \\
\text { BMI } \geq 35 \mathrm{~kg} / \mathrm{m}^{2} \\
(\mathrm{~N}=46)\end{array}$ & $P$ value \\
\hline Age (years) & $58(20-90)$ & $61(30-69)$ & $59(24-78)$ & $54(35-66)$ & \\
\hline Females (73) & $32(26.01 \%)$ & $30(36.58 \%)$ & $9(16.36 \%)$ & $2(4.34 \%)$ & 0.086 \\
\hline Diabetes (91) & $22(17.89 \%)$ & $31(37.80 \%)$ & $20(36.36 \%)$ & $18(39.13 \%)$ & 0.019 \\
\hline Hypertension (179) & $31(25.20 \%)$ & $77(93.90 \%)$ & $41(74.54 \%)$ & $30(65.22 \%)$ & 0.095 \\
\hline Death (58) & $17(13.82 \%)$ & $12(14.63 \%)$ & $14(25.45 \%)$ & $15(32.61 \%)$ & 0.039 \\
\hline
\end{tabular}


Two hundred and fifty-two patients $(82.35 \%)$ had at least some of the other coexisting condition, including hypertension (179 [58.49\%]), diabetes (91 [29.74\%]), cardiovascular disease (38 [12.42\%]), and COPD (106 [34.64\%]). One hundred and twenty-six patients (41.17\%) received some type of non-invasive ventilatory support including NIV and HFNC. Fifty-eight patients (18.95\%) received invasive mechanical ventilatory support, $209(68.30 \%)$ patients developed acute respiratory distress syndrome, and $25(8.16 \%)$ developed acute kidney injury. Of the 58 patients with invasive mechanical ventilation, $38(65.52 \%)$ were having BMI $>30 \mathrm{~kg} / \mathrm{m}^{2}$. Among 58 intubated patients, $31(53.44 \%)$ had a positive respiratory culture. Of 306 patients, $268(87.58 \%)$ had at least one blood culture sent; 23 (8.58\%) had bloodstream infections (BSIs), including five with polymicrobial BSI. Of these 23 patients, $11(47.83 \%)$ belonged to BMI $>30 \mathrm{~kg} / \mathrm{m}^{2}$. The most common source was the central line-associated BSI (10/23; 43.47\%). 54/306 (17.65\%) patients had some type of secondary infection with BMI $>30 \mathrm{~kg} / \mathrm{m}^{2}$ having the majority $(21 / 54[38.89 \%])$ of infections.

Overall, 58 patients $(18.96 \%)$ died within 14 days of ICU admission, $156(50.98 \%)$ were discharged alive or referred from the hospital within 14 days, and $92(30.06 \%)$ remained hospitalized at 14 days. The most common causes of death were a respiratory failure $(54[93.10 \%])$ and septic shock (21 [36.20\%]) with many patients having more than one cause.

The prevalence of overweight, obesity Class I, and obesity classes II and III among patients admitted to the ICU was $26.79 \%, 17.97 \%$, and $15.03 \%$, respectively, and the corresponding proportions among those who died were $14.63 \%, 25.45 \%$, and $32.61 \%(\mathrm{P}=0.039)$. After controlling for all covariates, there was a significantly increased risk of mortality in the patients with obesity Class I (RR 2.03, 95\% CI 1.07-3.85, P =0.030) and patients with obesity Classes II and III (RR 2.83, 95\% CI 1.54-5.22, P<0.001) compared with those with normal BMI [Table 2].

\begin{tabular}{|c|c|c|}
\hline Predictor & $\begin{array}{c}\text { Relative risk } \\
(95 \% \mathrm{Cl})\end{array}$ & $P$ value \\
\hline $\begin{array}{l}\text { Overweight } \\
\text { BMI } 25-29.9 \mathrm{~kg} / \mathrm{m}^{2}\end{array}$ & $1.19(0.61-2.31)$ & 0.528 \\
\hline $\begin{array}{l}\text { Obese Class I } \\
\text { BMI } 30-34.9 \text { kg/m² }\end{array}$ & $2.03(1.07-3.85)$ & 0.030 \\
\hline $\begin{array}{l}\text { Obese Classes II and III } \\
\mathrm{BMI} \geq 35 \mathrm{~kg} / \mathrm{m}^{2}\end{array}$ & $2.83(1.54-5.22)$ & 0.0008 \\
\hline Age $<65$ years & $2.92(1.11-7.82)$ & 0.063 \\
\hline Age $\geq 65$ years & $3.51(2.15-13.3)$ & 0.005 \\
\hline Female & $1.54(1.1-1.7)$ & 0.074 \\
\hline Diabetes & $1.2(0.84-1.4)$ & 0.656 \\
\hline Hypertension & $0.92(0.72-1.5)$ & 0.128 \\
\hline
\end{tabular}

\section{DISCUSSION}

This study revealed that obesity with BMI $>30 \mathrm{~kg} / \mathrm{m}^{2}$ is independently associated with adverse outcomes in COVID-19 patients when controlled for age, gender, hypertension, and diabetes. Obesity is a highly prevalent medical condition characterized by high BMI, that is, $\geq 30 \mathrm{~kg} / \mathrm{m}^{2}{ }^{21}$ It is associated with many diseases such as diabetes, hypertension, hypothyroidism, cardiovascular diseases, and increased risk of mechanical ventilation in association with other respiratory infectious diseases. ${ }^{12}$ Several studies investigating the association between BMI and mortality in hospitalized COVID-19 patients, observed an increased mortality rate in patients that were overweight (BMI $\geq 25$ to $<30 \mathrm{~kg} / \mathrm{m}^{2}$ ) or suffering from obesity $\left(\mathrm{BMI} \geq 30 \mathrm{~kg} / \mathrm{m}^{2}\right)$ or severe obesity (BMI $\left.\geq 35 \mathrm{~kg} / \mathrm{m}^{2}\right)^{13-16}$ One study by Demeulemeester et al. ${ }^{17}$ observed no difference in in-hospital deaths between normal and overweight (BMI $\left.>28 \mathrm{~kg} / \mathrm{m}^{2}\right)$ patients, but overweight patients did show more severe disease symptoms.

The present study included patients with confirmed COVID-19 in tertiary care designated COVID-19 hospital. The majority of patients were between 45 and 65 years of age with male predominance. This is comparable to one study from the USA by Garg et al., ${ }^{18}$ where among 1482 patients hospitalized with COVID-19, 74.5\% were aged $\geq 50$ years while the male percentage was $54.4 \%$.

Obesity (BMI $\geq 30 \mathrm{~kg} / \mathrm{m}^{2}$ ) was present in 101 patients $(33.00 \%)$ while $15(4.90 \%)$ Class III obesity $\left(\mathrm{BMI} \geq 40.0 \mathrm{~kg} / \mathrm{m}^{2}\right)$ patients were admitted to the ICU during the study period. In one study from Europe by Dana et al., ${ }^{19}$ obesity (BMI $\geq 30 \mathrm{~kg} / \mathrm{m}^{2}$ ) was present in 96 patients (43.24\%) and severe obesity (BMI $\geq 40 \mathrm{~kg} / \mathrm{m}^{2}$ ) in 16 patients $(7.2 \%)$. In the present study, nearly two-thirds of patients were diagnosed with acute respiratory distress syndrome. This is comparable to one study from China by Wu et al., ${ }^{20}$ where ARDS develops in $42 \%$ of patients presenting with COVID-19 pneumonia and $61-81 \%$ of those requiring intensive care.

In one study from Europe by Sjogren et al., ${ }^{21} 78.3 \%$ of patients in ICU with COVID-19 had a higher BMI and were either overweight or had obesity. In this study, 33.0\% of hospitalized patients with COVID-19 were obese, and $26.79 \%$ were overweight. The prevalence of obesity in our study was quite lower $(33.0 \%)$ than in studies performed in the USA (41.7-50.8\%) by Garg et al. ${ }^{18}$ and Kompaniyets et al..$^{22}$ This may be explained by the prevalence of obesity in the background population of $11.8-31.3 \%$ in India in 2015 by Ahirwar and Mondal ${ }^{6}$ and $40.2 \%$ in the USA in 2017-2018 by Hales et al. ${ }^{15}$ The pathogeneses linked between increased BMI and severe COVID-19 could be 
immune dysregulation, presence of one or more additional conditions, and a compromised respiratory system as per study by Costela-Ruiz et al. ${ }^{23}$

Covariate analysis showed age $\geq 65$ years to be significant independent predictors of mortality when controlling for other confounders, however, female sex was not a significant independent predictor of mortality as found in a similar type of a study by Nakeshbandi et al. ${ }^{2}$ In the present study, $17.65 \%$ of patients had some type of secondary infection in comparison to one study by Al-Salameh et al., ${ }^{24}$ where it was $23.4 \%$. COVID-19 patient with a high BMI has increased risk of secondary infections, especially nosocomial pneumonia. Despite many studies establishing obesity associated with a greater risk of catheter and bloodstream infections, surgical site infections, wound infections, and infections of the urinary tract, the studies by Mancuso ${ }^{25}$ and Zhou et al., ${ }^{13}$ on the association between obesity and the risk of nosocomial pneumonia, which is most often caused by bacteria, are mixed.

We found that the frequency of death among patients with COVID-19 was twice $(28.71 \%)$ as high for obese (BMI $>30 \mathrm{~kg} / \mathrm{m}^{2}$ ) individuals than for individuals with BMI $<25 \mathrm{~kg} / \mathrm{m}^{2}(13.82 \%)$. Obesity was significantly associated with a greater likelihood of occurrence of the primary endpoint (death), and a maximum percentage of death $(32.61 \%)$ was noted in obesity Classes II and III (BMI $\geq 35 \mathrm{Kg} / \mathrm{m}^{2}$ ). Group Class I (BMI 18.5-24.9 Kg/m²) had the least percentage of meeting the primary endpoint. In a large cohort of Swedish ICU patients with COVID-19, a high BMI was associated with an increased risk of death and prolonged length of stay in the ICU in a study by Sjogren et al. ${ }^{21}$ As per recent study from India by Gupta et al., ${ }^{26}$ for assessing the case fatality and recovery in critically ill COVID-19 patients with systemic comorbidities, we have to audit the mortality and recovery statistics in a better way.

\section{Limitations of the study}

Our study had several limitations: The residual presence of confounding factors cannot be ruled out. Waist circumference as a measure of obesity was not available.

\section{CONCLUSION}

We found that obesity was associated with an unfavorable outcome among patients with COVID-19. Individuals with obesity should be more closely monitored when hospitalized for COVID-19 as there is increasing evidence of relation of severity of COVID-19 and obesity which appears to be a factor in the health risks.

\section{ACKNOWLEDGMENTS}

The authors would like to appreciate the involvement of supporting staff in this study from Government Institute of Medical Sciences, Greater Noida, Uttar Pradesh, India.

\section{REFERENCES}

1. Ryu BH, Hong SI, Lim SJ, Cho Y, Hwang C, Kang H, et al. Clinical features of adult COVID-19 patients without risk factors before and after the nationwide SARS-CoV-2 B.1.617.2 (delta)variant outbreak in Korea: Experience from Gyeongsangnamdo. J Korean Med Sci. 2021;36(49):e341.

https//doi.org/10.3346/jkms.2021.36.e341

2. Nakeshbandi $M$, Maini $R$, Daniel $P$, Rosengarten $S$, Parmar P, Wilson C, et al. The impact of obesity on COVID-19 complications: A retrospective cohort study. Int J Obes (Lond). 2020;44(9):1832-1837. https//doi.org/10.1038/s41366-020-0648-x

3. Nazir N and Gupta S. Preparing for a COVID-19 pandemic: A review of operating room outbreak response measures in a large tertiary hospital in India. Ain-Shams $\mathrm{J}$ Anesthesiol. 2021;13:30.

https//doi.org/10.1186/s42077-021-00150-w

4. Albashir AA. The potential impacts of obesity on COVID-19. Clin Med (Lond). 2020;20(4):e109-e113.

https//doi.org/10.7861/clinmed.2020-0239

5. Simonnet A, Chetboun M, Poissy J, Raverdy V, Noulette J, Duhamel $A$, et al. High prevalence of obesity in severe acute respiratory syndrome coronavirus-2 (SARS-CoV-2) requiring invasive mechanical ventilation. Obesity (Silver Spring) 2020;28(7):1195-1199.

https//doi.org/10.1002/oby.22831

6. Ahirwar R and Mondal PR. Prevalence of obesity in India: Asystematic review. Diabetes Metab Syndr. 2019;13(1):318-321. https//doi.org/10.1016/j.dsx.2018.08.032

7. Nie $\mathrm{W}$, Zhang $\mathrm{Y}$, Jee $\mathrm{SH}$, Jung $\mathrm{KJ}$, Li B and Xiu Q. Obesity survival paradox in pneumonia: A meta-analysis. BMC Med. 2014;12:61.

https//doi.org/10.1186/1741-7015-12-61

8. Stefan N, Birkenfeld AL, Schulze MB and Ludwig DS. Obesity and impaired metabolic health in patients with COVID-19. Nat Rev Endocrinol. 2020;16(7):341-342.

https//doi.org/10.1038/s41574-020-0364-6

9. Xie J, Wu W, Li S, Hu Y, Hu M, Li J, et al. Clinical characteristics and outcomes of critically ill patients with novel coronavirus infectious disease (COVID-19) in China: A retrospective multicenter study. Intensive Care Med. 2020;46(10):1863-1872. https//doi.org/10.1007/s00134-020-06211-2

10. Vittinghoff E, Glidden DV, Shiboski SC and McCulloch CE. Regression Methods in Biostatistics: Linear, Logistic, Survival, and Repeated Measures Models. New York: Springer; 2015.

11. Leitner DR, Fruhbeck G, Yumuk V, Schindler K, Micic D, Woodward E, et al. Obesity and Type 2 diabetes: Two diseases with a need for combined treatment strategies EASO can lead the way. Obes Facts. 2017;10(5):483-492. https//doi.org/10.1159/000480525

12. Williamson EJ, Walker AJ, Bhaskaran K, Bacon S, Bates C, Morton CE, et al. Factors associated with COVID-19-related death using OpenSAFELY. Nature. 2020;584(7821):430-436. 
https//doi.org/10.1038/s41586-020-2521-4

13. Zhou F, Yu T, Du R, Fan G, Liu Y, Liu Z, et al. Clinical course and risk factors for mortality of adult inpatients with COVID-19 in Wuhan, China: a retrospective cohort study. Lancet Lond Engl. 2020;395(10229):1054-1062.

https//doi.org/10.1016/S0140-6736(20)30566-3

14. Caussy C, Pattou F, Wallet F, Simon C, Chalopin S, Telliam C, et al. Prevalence of obesity among adult inpatients with COVID-19 in France. Lancet Diabetes Endocrinol. 2020;8(7):562-564. https//doi.org/10.1016/S2213-8587(20)30160-1

15. Hales CM, Carroll MD, Fryar CD and Ogden CL. Prevalence of obesity and severe obesity among adults: United States, 2017-2018. NCHS Data Brief. 2020;360:1-8.

16. Mahase E. Covid-19: Most patients require mechanical ventilation in first $24 \mathrm{~h}$ of critical care. BMJ. 2020;368:m1201. https//doi.org/10.1136/bmj.m1201

17. Demeulemeester $F$, de Punder $K$, van Heijningen $M$ and van Doesburg F. Obesity as a risk factor for severe COVID-19 and complications: A review. Cells. 2021;10(4):933. https//doi.org/10.3390/cells10040933

18. Garg S, Kim L, Whitaker M, O'Halloran A, Cummings C, Holstein R, et al. Hospitalization rates and characteristics of patients hospitalized with laboratory-confirmed coronavirus disease 2019 COVID-NET, 14 States, March 1-30, 2020. MMWR Morb Mortal Wkly Rep. 2020;69(15):458-464. https//doi.org/10.15585/mmwr.mm6915e3

19. Dana R, Bannay A, Bourst P, Ziegler C, Losser MR, Gibot S, et al. Obesity and mortality in critically ill COVID-19 patients with respiratory failure. Int J Obes (Lond). 2021;45(9):2028-2037. https//doi.org/10.1038/s41366-021-00872-9

20. Wu C, Chen X, Cai Y, Xia J, Zhou X, Xu S, et al. Risk Factors associated with acute respiratory distress syndrome and death in patients with coronavirus disease 2019Pneumonia in Wuhan, China. JAMA Intern Med. 2020;180(7):934-943.

https//doi.org/10.1001/jamainternmed.2020.0994

21. Sjogren L, Stenberg E, Thuccani M, Martikainen J, Rylander C, Wallenius $\mathrm{V}$, et al. Impact of obesity on intensive care outcomes in patients with COVID-19 in Sweden a cohort study. PLoS One. 2021;16(10):e0257891.

https//doi.org/10.1371/journal.pone.0257891

22. Kompaniyets L, Goodman AB, Belay B, Freedman DS, Sucosky MS, Lange SJ, et al. Body mass index and risk for COVID-19-related hospitalization, intensive care unit admission, invasive mechanical ventilation, and death-United States, March-December 2020. MMWR Morb Mortal Wkly Rep 2021;70(10):355-361.

23. Costela-Ruiz VJ, Illescas-Montes R, Puerta-Puerta JM, Ruiz C and Melguizo-Rodríguez L. SARS-CoV-2 infection: The role of cytokines in COVID-19 disease. Cytokine Growth Factor Rev. 2020;54:62-75.

https//doi.org/10.1016/j.cytogfr.2020.06.001

24. Al-Salameh A, Lanoix JP, Bennis Y, Andrejak C, Brochot E, Deschasse $\mathrm{G}$, et al. The association between body mass index class and coronavirus disease 2019 outcomes. Int J Obes (Lond). 2021;45(3):700-705. https//doi.org/10.1038/s41366-020-00721-1

25. Mancuso P. Obesity and respiratory infections: Does excess adiposity weigh down host defense? Pulm Pharmacol Ther 2013;26(4):412-419. https//doi.org/10.1016/j.pupt.2012.04.006

26. Gupta N and Lohani S. Case fatality and recovery rate of COVID 19: What are we missing? Indian J Anaesth. 2021;65(Suppl 2):95-97. https//doi.org/10.4103/ija.IJA_59_21

\section{Authors Contribution:}

SG- Concept and design of the study, data acquisition, interpreted the results, reviewed the literature and manuscript, and prepared first draft of manuscript;

VG- Statistical analysis and interpretation, data acquisition, preparation and editing of manuscript; and NN, SS, and AS- Reviewed the literature and manuscript

\section{Work attributed to:}

Government Institute of Medical Sciences, Greater Noida - 201 310, Uttar Pradesh, India

Orcid ID:

Dr. Savita Gupta - (1) https://orcid.org/0000-0002-3104-7368

Dr. Varun Goel - (D https://orcid.org/0000-0002-9194-727X

Dr. Nazia Nazir - (1) https://orcid.org/0000-0001-6950-2111

Dr. Saurabh Srivastava - (i) https://orcid.org/0000-0002-1700-8856

Dr. Anurag Srivastava - (10 https://orcid.org/0000-0002-7894-2976

Source of Funding: None, Conflicts of Interest: None. 